\title{
Phylogenetic analyses of bat-associated bugs (Hemiptera: Cimicidae: Cimicinae and Cacodminae) indicate two new species close to Cimex lectularius
}

Sándor Hornok ${ }^{1 *}$ (D) Krisztina Szőke ${ }^{1}$, Sándor A. Boldogh², Attila D. Sándor ${ }^{3}$, Jenő Kontschán ${ }^{4}$, Vuong Tan Tu ${ }^{5}$, Ali Halajian ${ }^{6}$, Nóra Takács ${ }^{1}$, Tamás Görföl ${ }^{7}$ and Péter Estók ${ }^{8}$

\begin{abstract}
Background: Bats are regarded as the primary (ancestral) hosts of bugs of the family Cimicidae. The historically and economically most important species in the family is the common bedbug (Cimex lectularius), because of its worldwide occurrence and association with humans. This molecular-phylogenetic study was initiated in order to expand the knowledge on the phylogeny of cimicid bugs of bats, by investigating samples from Hungary, Romania (representing central-eastern Europe) and two further countries (South Africa and Vietnam).

Results: Altogether 216 cimicid bugs were collected (73 Ci. lectularius, 133 Ci. pipistrelli, nine Cacodmus ignotus and one Ca. sparsilis). Members of the Cimex lectularius species group were found both in the environment of bats (only Myotis emarginatus, which is a cave/attic-dwelling species) and on three crevice-dwelling bat species (two pipistrelloid bats and M. bechsteinii). On the other hand, Ci. pipistrelli always occurred off-host (near M. myotis/blythii, which are cave/atticdwelling species). In addition, two Cacodmus spp. were collected from Pipistrellus hesperidus. The morphological characters of these specimens are illustrated with high resolution pictures. Analysis of cytochrome $c$ oxidase subunit 1 (cox 1 ) sequences generated from 38 samples indicated relative genetic homogeneity of Ci. pipistrelli, while the Ci. lectularius group had two haplotypes (collected from pipistrelloid bats in Hungary and Vietnam) highly divergent from other members of this species group. These results were confirmed with molecular and phylogenetic analyses based on the internal transcribed spacer 2 (ITS2). Bat-associated bugs morphologically identified as Ca. ignotus and Ca. sparsilis were different in their cox1, but identical in their ITS2 sequences.

Conclusions: Molecular evidence is provided here on the existence of two new genotypes, most likely new species, within the Ci. lectularius species group. The relevant specimens (unlike the others) were collected from pipistrelloid bats, therefore the association of Ci. lectularius with different bat host species (pipistrelloid vs myotine bats) should be evaluated further as a possible background factor of this genetic divergence. In addition, Ca. ignotus is reported for the first time in South Africa.
\end{abstract}

Keywords: Cytochrome c oxidase subunit 1, cox1, Internal transcribed spacer 2, ITS2, Cacodmus, Cimex pipistrelli

\footnotetext{
* Correspondence: hornok.sandor@univet.hu

'Department of Parasitology and Zoology, University of Veterinary Medicine,

Budapest, Hungary

Full list of author information is available at the end of the article
} 


\section{Background}

Cimicid bugs (Hemiptera: Cimicidae) include approximately 110 described species [1], which are obligate, haematophagous ectoparasites of birds and mammals. Bats are regarded as the primary (ancestral) hosts of bugs in the Cimicidae, with subsequent switches to other hosts, including birds and humans [2-4]. This is well reflected by the fact that the majority (approx. twothirds) of cimicid species are bat-associated $[2,5]$.

The historically and economically most important species in the family is the common bedbug (Cimex lectularius), because of its worldwide occurrence and preference of human environment. While the number of reported cases of bedbug infestations had been showing a decline until the middle of twentieth century, during the last two decades $\mathrm{Ci}$. lectularius became an emerging pest even in highly developed countries [6]. This is the most important aspect that may illustrate the growing significance of this species, but not the only one. Cimex lectularius is the potential vector of at least 65 pathogens [6], but its vector competency awaits verification.

The morphology of cimicid bugs is frequently a matter of controversy. For instance, in the $\mathrm{Ci}$. pipistrelli group, the morphological characters intended to delineate species were shown to vary significantly enough to ascribe progeny of the same female to different species [5, 7]. Accordingly, the taxonomy of bat-associated bugs is currently in a state of transition. While some formerly distinguished Cimex species are suggested to be synonymous (as exemplified by $C i$. pipistrelli and $C i$. dissimilis, see [5]), new species are also discovered/described [8]. The genus Oeciacus (associated with birds) has been transferred to Cimex [4]. These and other examples highlight the importance of molecular phylogenetic studies focusing on cimicid bugs, which recently have started to expand $[5,9]$.

Bat-associated bugs, as well as other cimicid bugs, are temporary ectoparasites, which spend most of their life offhost. On the other hand, bat-associated bugs are unable to fly, therefore strictly rely on their hosts for colonization of new habitats, as well as for distribution over large distances $[5,10]$. Cimicid bug species associated with bats show different host ranges $[2,11]$. Adaptation to host species has been suggested to be a driver of morphological rather than genetic diversification in the case of $\mathrm{Ci}$. pipistrelli [5]. At the same time, host preference will also influence the small-scale (habitat-related) as well as large-scale (geographical) distribution of bat-associated bugs $[9,11,12]$.

While $\mathrm{Ci}$. lectularius, as a man-associated parasite, has a worldwide geographical distribution $[6,9]$, accounts of its bat-related lineages concentrate in the Western Palaearctic $[9,11]$. In this region a recent phylogeographic study on $\mathrm{Ci}$. lectularius revealed that this species is currently undergoing lineage divergence through host association [9]. However, in the latter survey Hungary was underrepresented, and in another comprehensive survey on bat-associated bugs [5] the Balkans and other regions of the Old World had not been included. This molecular-phylogenetic study was initiated in order to expand the knowledge on the phylogeny of cimicid bugs of bats, by investigating samples from Hungary, Romania (the latter representing the Balkans) and two further countries (South Africa and Vietnam).

\section{Methods}

\section{Sample collection and study design}

Bat-associated cimicid bugs were collected in Hungary (six locations), Romania (two locations), South Africa (one location) and Vietnam (one location) between 2011 and 2016 (Table 1). The bats were caught for monitoring and ringing purposes at cave entrances from sunset to dawn, using harp traps or Ecotone mist-nets (Gdynia, Poland) with standard $12 \mathrm{~m}$ length, $2.5 \mathrm{~m}$ height and $14 \times 14 \mathrm{~mm}$ mesh size. Bats were released immediately after parasite removal and recording data (date and place of collection, bat species). Alternatively, the close environment of nursing bat colonies with different habitat types (Table 1) was checked for the presence of Cimicidae. The bugs were immediately placed into and stored in 96\% ethanol.

Concerning study design, because the size of structures important for morphological identification of cimicid bugs was shown to exhibit significant intraspecific variation $[2,5]$, detailed measurements were not taken, and only discrete morphological characters were considered for species identification.

Morphological identification of adult bugs was carried out under a stereomicroscope (SMZ-2 T, Nikon Instruments, Japan) by using standard keys [2], focusing on the pronotum, paragenital sinus (Cimex spp.) or the paramere (Cacodmus spp.). Concerning samples (one from Hungary and two from Vietnam), which showed high degrees of genetic divergences from other members of their phylogenetic group, their conspecificity with $\mathrm{Ci}$. emarginatus (reported in Bulgaria) and $\mathrm{Ci}$. insuetus (reported in Thailand), respectively, was excluded based on descriptions of the latter species $[8,13]$. Cacodmus sp. females were identified according to the cox 1 sequences of morphologically identified males. Pictures were made with a VHX-5000 (Keyence Co., Osaka, Japan) digital microscope.

\section{DNA extraction and molecular analyses}

DNA was extracted from individual bugs with the QIAamp DNA Mini Kit (Qiagen, Hilden, Germany) according to the manufacturer's instruction, including an overnight digestion in tissue lysis buffer and Proteinase- $\mathrm{K}$ at $56{ }^{\circ} \mathrm{C}$. Molecular phylogenetic analysis was attempted from 44 samples, including 1-10 adult bugs from each location.

The cytochrome $c$ oxidase subunit 1 (cox1) gene was chosen as the primary target for molecular analysis, on 
Table 1 Data for the samples used in this study

\begin{tabular}{|c|c|c|c|c|c|c|c|c|}
\hline \multirow{2}{*}{$\begin{array}{l}\text { Bug species or species } \\
\text { group }\end{array}$} & \multirow[t]{2}{*}{ Country } & \multirow{2}{*}{$\begin{array}{l}\text { Location (no. of samplings } \\
\times \text { habitat type) }\end{array}$} & \multirow[t]{2}{*}{ Host nearby ('on host) } & \multicolumn{3}{|l|}{ Stage } & \multicolumn{2}{|c|}{ GenBank ID (no. of samples amplified) } \\
\hline & & & & Nymph & Female & Male & $\operatorname{cox} 1$ & ITS2 \\
\hline \multirow[t]{6}{*}{ Cimex lectularius group } & Hungary & Dráva $(1 \times A)$ & Myotis emarginatus & 1 & 3 & 4 & MF161525 (2X) & ns \\
\hline & & Trizs $(3 \times \mathrm{CH})$ & & 13 & 19 & 23 & $\begin{array}{l}\text { MF161526 (2x); } \\
\text { MF161527 (6x) }\end{array}$ & $\begin{array}{l}\text { MF161534 (2x); } \\
\text { MF161535 (1x) }\end{array}$ \\
\hline & & Ragály $(1$ × LH) & & 1 & 4 & 1 & MF161522 (3x) & MF161535 (1×) \\
\hline & & Nagyvisnyó (1) & Pipistrellus pipistrellus ${ }^{\mathrm{a}}$ & 0 & 1 & 0 & MF161521 (1X) & MF161532 (1x) \\
\hline & & Noszvaj (1) & Myotis bechsteinii ${ }^{a}$ & 0 & 0 & 1 & MF161520b (1X) & ns \\
\hline & Vietnam & Thanh Hoa, Ngoc Khe (1) & Hypsugo pulveratus ${ }^{\mathrm{a}}$ & 0 & 1 & 1 & MF415647 (1×) & MF161540 (1×) \\
\hline \multirow[t]{3}{*}{ Cimex pipistrelli } & Hungary & Szőlősardó (2 × CH) & Myotis myotis/blythii & 3 & 2 & 4 & $\operatorname{MF} 161523^{b}(5 \times)$ & 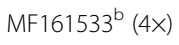 \\
\hline & Romania & Sant $(1 \times M)$ & Myotis myotis & 1 & 0 & 0 & nd & nd \\
\hline & & Leghia $(6 \times M)$ & Myotis blythii & 32 & 49 & 42 & $\begin{array}{l}\text { MF161524 (5x); } \\
\text { MF161528 (2x) }\end{array}$ & $\begin{array}{l}\text { MF161536 (2x); } \\
\text { MF161537 (1X) }\end{array}$ \\
\hline Cacodmus ignotus & $\begin{array}{l}\text { South } \\
\text { Africa }\end{array}$ & Makhado (2) & Pipistrellus hesperidus ${ }^{\mathrm{a}}$ & 0 & 2 & 7 & $\begin{array}{l}\text { MF161529b (8x); } \\
\text { MF161530 (1x) }\end{array}$ & MF161538 $(2 \times)$ \\
\hline Cacodmus sparsilis & & & & 0 & 0 & 1 & MF161531 (1×) & MF161539 (1×) \\
\hline
\end{tabular}

Abbreviations: $A$ attic, $C H$ church tower, $L H$ lich house, $M$ mine, $n$ s not successful, $n d$ not done

${ }^{\mathrm{a} O n}$ host

bused as reference sequence of the given bug species in the text

account of its suitability as a DNA-barcode sequence for cimicid bug species [3]. The PCR amplifies a 658 bp long fragment of the $\operatorname{cox} 1$ gene of various insect orders. The primers Lep1F (5' -ATT CAA CCA ATC ATA AAG ATA TTG G-3'), Lep1Fdeg (5'-ATT CAA CCA ATC ATA AAG ATA TNG G-3') and Lep3R (5'-TAT ACT TCA GGG TGT CCG AAA AAT CA-3') [4] were used in a reaction volume of $25 \mu \mathrm{l}$, containing $1 \mathrm{U}(0.2 \mu \mathrm{l})$ HotStarTaq Plus DNA polymerase, $2.5 \mu \mathrm{l} 10 \times$ CoralLoad Reaction buffer (including $15 \mathrm{mM} \mathrm{MgCl}_{2}$ ), $0.5 \mu \mathrm{l}$ PCR nucleotide Mix (0.2 mM each), $0.25 \mu \mathrm{l}(0.5 \mu \mathrm{M}$ final concentration) of each Lep1F and Lep1Fdeg primers and $0.5 \mu \mathrm{l}(1 \mu \mathrm{M}$ final

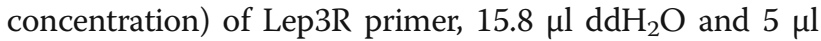
template DNA. For amplification, an initial denaturation step at $95{ }^{\circ} \mathrm{C}$ for $5 \mathrm{~min}$ was followed by 40 cycles of denaturation at $94{ }^{\circ} \mathrm{C}$ for $40 \mathrm{~s}$, annealing at $53{ }^{\circ} \mathrm{C}$ for $1 \mathrm{~min}$ and extension at $72{ }^{\circ} \mathrm{C}$ for $1 \mathrm{~min}$. Final extension was performed at $72{ }^{\circ} \mathrm{C}$ for $10 \mathrm{~min}$. In addition, a similar length fragment of the cox 1 gene of the sample from Vietnam was amplified with the primers HCO2198 (5' -TAA ACT TCA GGG TGA CCA AAA AAT CA-3') and LCO1490 (5'-GGT CAA CAA ATC ATA AAG ATA TTG G-3') [14] as reported [15].

To complement the results obtained with the mitochondrial cox1 gene, 16 samples that showed different cox 1 haplotype within a country, were also tested for a nuclear marker, the internal transcribed spacer 2 (ITS2). This PCR amplifies a $\sim 1027$ bp fragment of the ITS2 of Hemiptera [16], with the primers CAS5p8sFc (5'-GCG AAC ATC GAC AAG TCG AAC GCA CAT-3') and CAS28sB1d (5'-TTG TTT TCC TCC GCT TAT TAA TAT GCT TAA-3'). Five $\mu \mathrm{l}$ of template DNA were added to $20 \mu \mathrm{l}$ reaction mixture, containing $1 \mathrm{U}(0.2 \mu \mathrm{l})$
HotStarTaq Plus DNA polymerase, $2.5 \mu \mathrm{l} 10 \times$ CoralLoad Reaction buffer (including $15 \mathrm{mM} \mathrm{MgCl}_{2}$ ), $0.5 \mu \mathrm{PCR}$ nucleotide Mix (0.2 mM each), $0.5 \mu \mathrm{l}(1 \mu \mathrm{M}$ final concentration) of each primers and $15.8 \mu \mathrm{l} \mathrm{ddH}_{2} \mathrm{O}$. An initial denaturation step at $95{ }^{\circ} \mathrm{C}$ for 5 min was followed by 35 cycles of denaturation at $95^{\circ} \mathrm{C}$ for $30 \mathrm{~s}$, annealing at $59^{\circ} \mathrm{C}$ for $40 \mathrm{~s}$ and extension at $72{ }^{\circ} \mathrm{C}$ for $1 \mathrm{~min}$. Final extension was performed at $72{ }^{\circ} \mathrm{C}$ for $7 \mathrm{~min}$.

PCR products were visualized in $1.5 \%$ agarose gel. Purification and sequencing were done by Biomi Inc. (Gödöllö, Hungary). Obtained sequences were manually edited, then aligned and compared to reference GenBank sequences by nucleotide BLASTN program (https://blast.ncbi.nlm.nih.gov). Representative sequences (including identical haplotypes from different locations) were submitted to GenBank (accession numbers: MF161520-MF161531 for cox1, and MF161532-MF161540 for ITS2). Phylogenetic analyses were conducted by using MEGA version 6.0, with the Maximum Likelihood method and the model (Tamura 3) selected by the program.

\section{Results}

\section{General morphology and host species of bat-associated bugs}

Altogether 216 cimicid bugs were collected from the bodies or roosts of seven bat species of three genera (Table 1). Bugs morphologically most closely related to Cimex lectularius were found both in the environment of bats and on the bat species Pipistrellus pipistrellus, Myotis bechsteinii and Hypsugo pulveratus. On the other hand, Ci. pipistrelli occurred only off-host (Table 1).

The Cimex lectularius species group was represented by 73 specimens. These showed similar general morphological 
characters if collected near bats (Fig. 1) or from bats in Hungary (Figs. 2 and 3b), including the shape of the pronotum (breadth to length ratio $\geq 2.5$, broad lateral lobes), paragenital sinus (cleft with bristles) and external spur on coxa III (with a broad basis). However, while the pronotum and coxal spur were similar in the case of specimens from Hungary (Fig. 3a-c) and Vietnam (Fig. 3d), the paragenital sinus of the female bug from Vietnam was rounded (Fig. 4d).

Cimex pipistrelli was represented by 133 specimens (Table 1). All of these from Hungary and Romania shared the shape of the pronotum (breadth to length ratio $<2.5$, narrow lateral lobes) and of the paragenital sinus (cleft and naked) (Fig. 5).

Cacodmus sp. males from South Africa had either evenly curved and tapering, apically straight, medium to long paramere (Fig. 6c-d), or long paramere bent laterally at the tip (almost sinuate at apex) (Fig. 6b). On this basis specimens were assigned to Ca. ignotus and Ca. sparsilis, respectively.

\section{Sequence comparison and phylogeny of bat-associated bugs} The cox 1 gene fragment was successfully amplified and sequenced from 38 samples (Table 1). Bugs morphologically most closely related to Ci. lectularius (15 samples) had four cox1 haplotypes in Hungary. The majority of these exhibited up to five nucleotide differences from each other, corresponding to $99.2-100 \%$ sequence similarity (626-631/631 bp). However, a Cimex sp. from $P$. pipistrellus (Hungary) showed 46 nucleotide differences from the Ci. lectularius reference sequence (MF161520: from Hungary), i.e. only 585/631 bp (92.7\%) sequence similarity. The cox 1 gene fragment of another Cimex sp. from Vietnam revealed an even lower, 522/631 bp (82.7\%) sequence similarity with $\mathrm{C} i$. lectularius.

Bugs identified as $\mathrm{C} i$. pipistrelli (represented by 12 samples) had three cox 1 haplotypes. These exhibited up to six nucleotide differences from each other, amounting to $99-100 \%$ sequence similarity (625-631/631 bp). Cacodmus ignotus from South Africa had two cox 1 haplotypes, with only one nucleotide difference (630-631/ 631 bp, i.e. $99.8-100 \%$ similarity). The bug identified as Ca. sparsilis showed 43 nucleotide divergence from $\mathrm{Ca}$. ignotus (588/631 bp, i.e. $93.2 \%$ similarity).

The ITS2 fragment was successfully amplified and sequenced from 16 samples (Table 1). In general, this nuclear marker showed a much lower degree of intraspecific divergence compared to cox1. Members of the Cimex lectularius group from Hungary had only two different ITS2 haplotypes. However, the Cimex sp. from $P$. pipistrellus (Hungary) showed only $96.7 \%$ (622/643 bp) sequence similarity in its longest region of continuous alignment with the ITS2 reference sequence (MF161534: from Hungary). In addition, the Cimex sp. from Vietnam showed even lower, $88.3 \%$ (580/657 bp) sequence similarity in its longest region of alignment with the ITS2 reference sequence.

Cimex pipistrelli had two nearly identical ITS2 sequences (941-942/942 bp, i.e. 99.9-100\% similarity). Unexpectedly, samples identified as Ca. ignotus and $\mathrm{Ca}$. sparsilis, which showed only $93.2 \%$ cox 1 sequence similarity, were identical in their ITS2.

The phylogenetic relationships of $\operatorname{cox} 1$ and ITS2 sequences are shown in Figs. 7 and 8, respectively. The separation of the Cimex specimen (collected from $\mathrm{Pi}$. pipistrellus in Hungary) from other isolates of the $\mathrm{Ci}$.
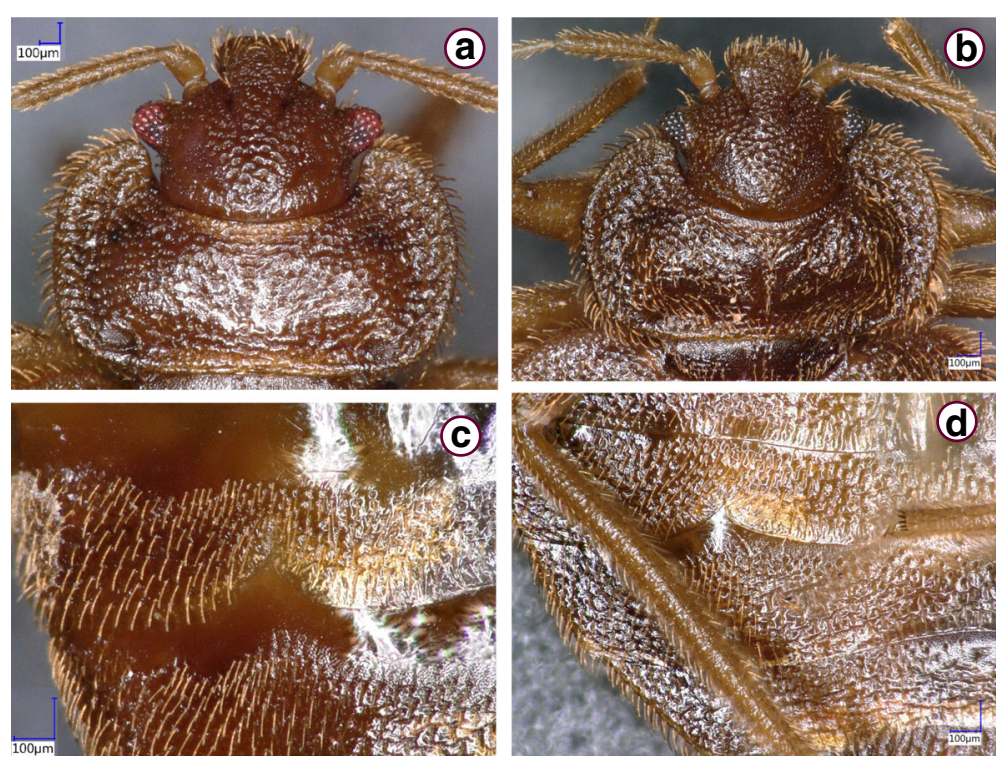

Fig. 1 Cimex lectularius, females collected near Myotis emarginatus, in three locations of Hungary: Dráva (a, c); Trizs (b); and Ragály (d). a, b Head and pronotum. c, d Paragenital sinus 

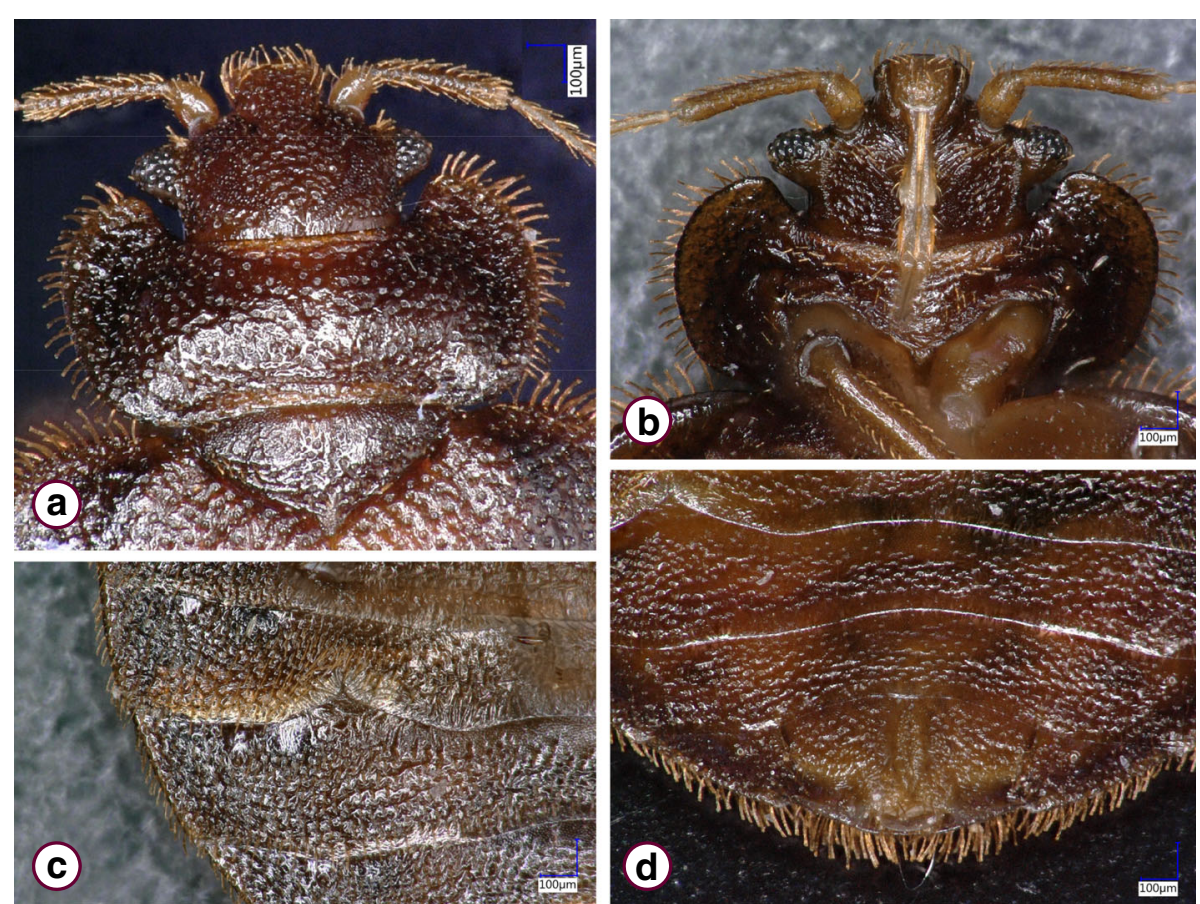

Fig. 2 Cimex sp., female collected from Pipistrellus pipistrellus in Hungary (Nagyvisnyó). a Head and pronotum, dorsal view. b Head and pronotum, ventral view. c Paragenital sinus. d Last two abdominal segments
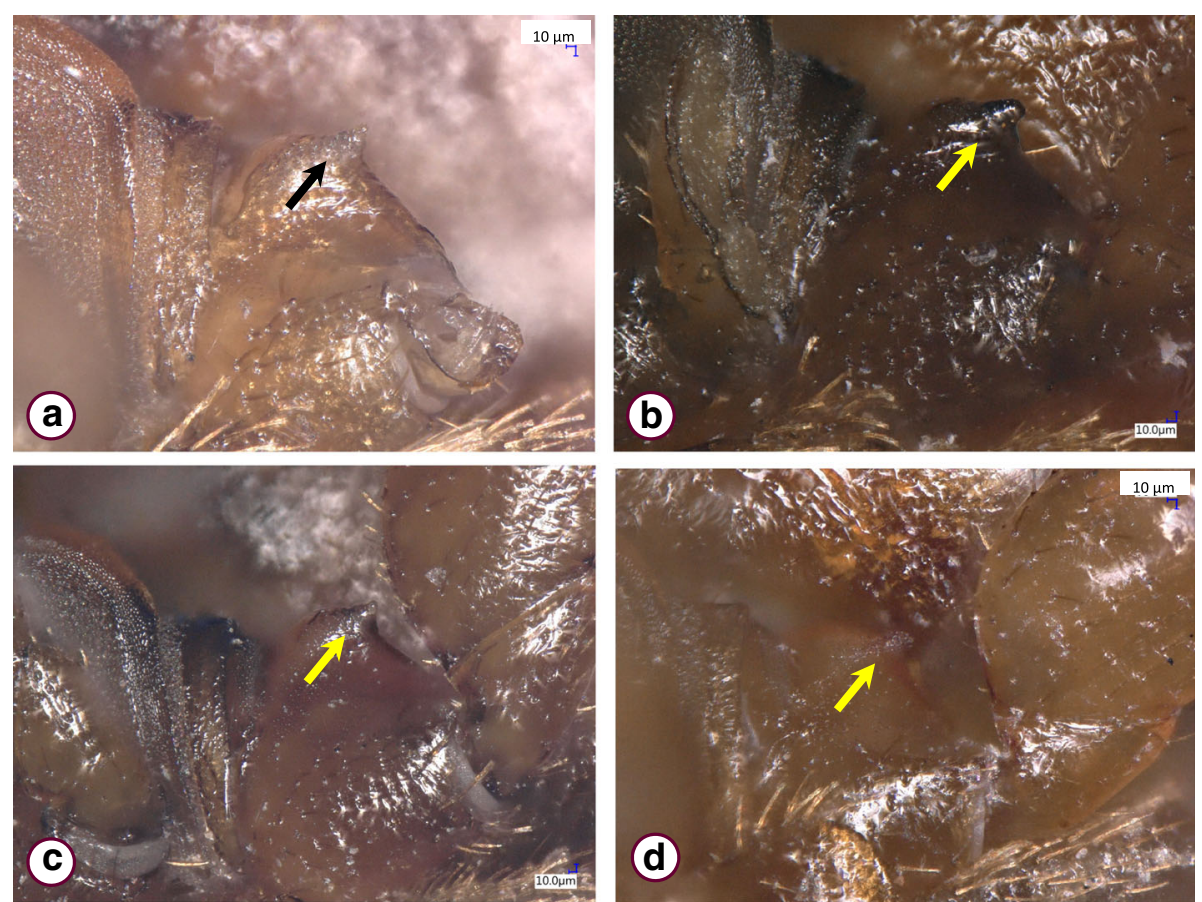

Fig. 3 Cimex lectularius, broad basis (arrow) of external spur on coxa III. Specimens collected in Hungary from Pipistrellus pipistrellus (Nagyvisnyó) (a) and Myotis bechsteinii (Noszvaj) (b); in a human dwelling (Budapest, Neptun street) (c); and a specimen collected in Vietnam from Hypsugo pulveratus (d) 


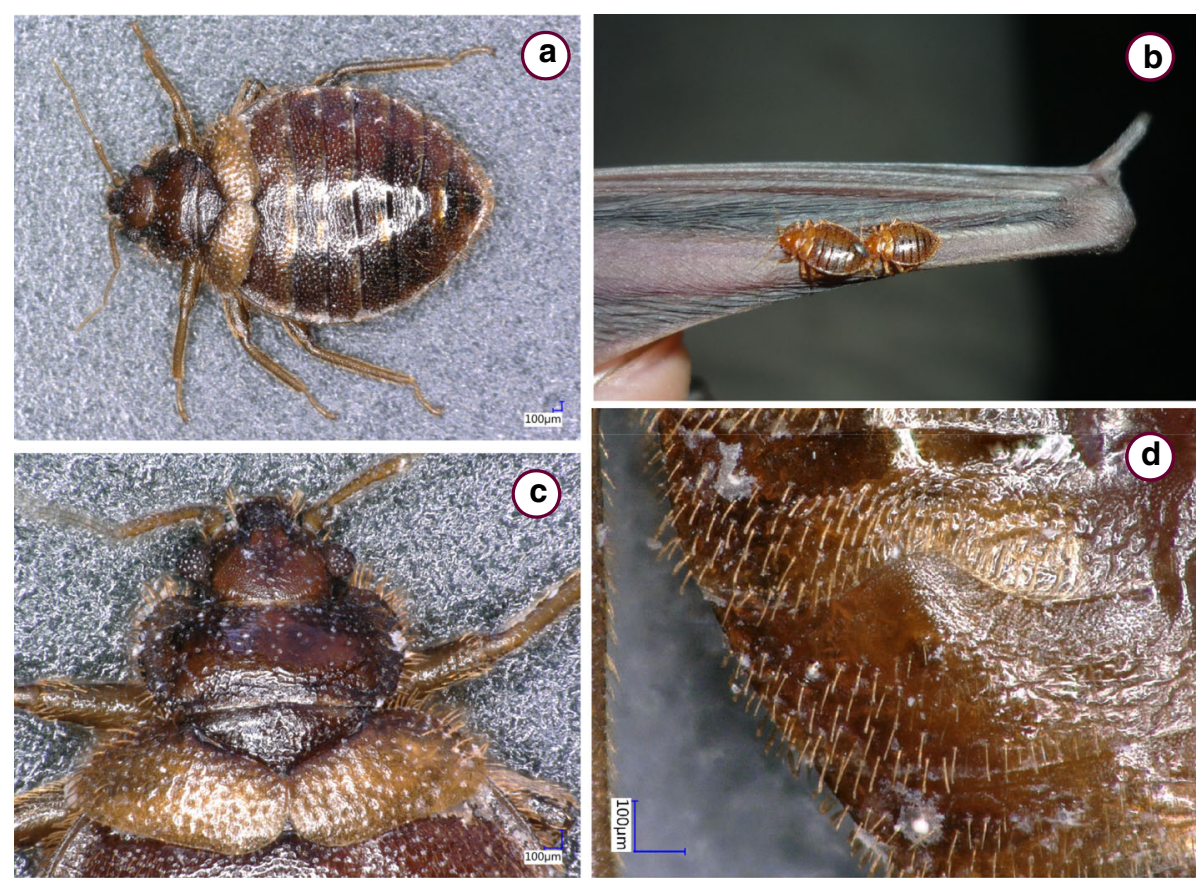

Fig. 4 Cimex sp., female collected from Hypsugo pulveratus in Vietnam. a Habitus. b In situ on bat patagium. c Head and pronotum. d Paragenital sinus
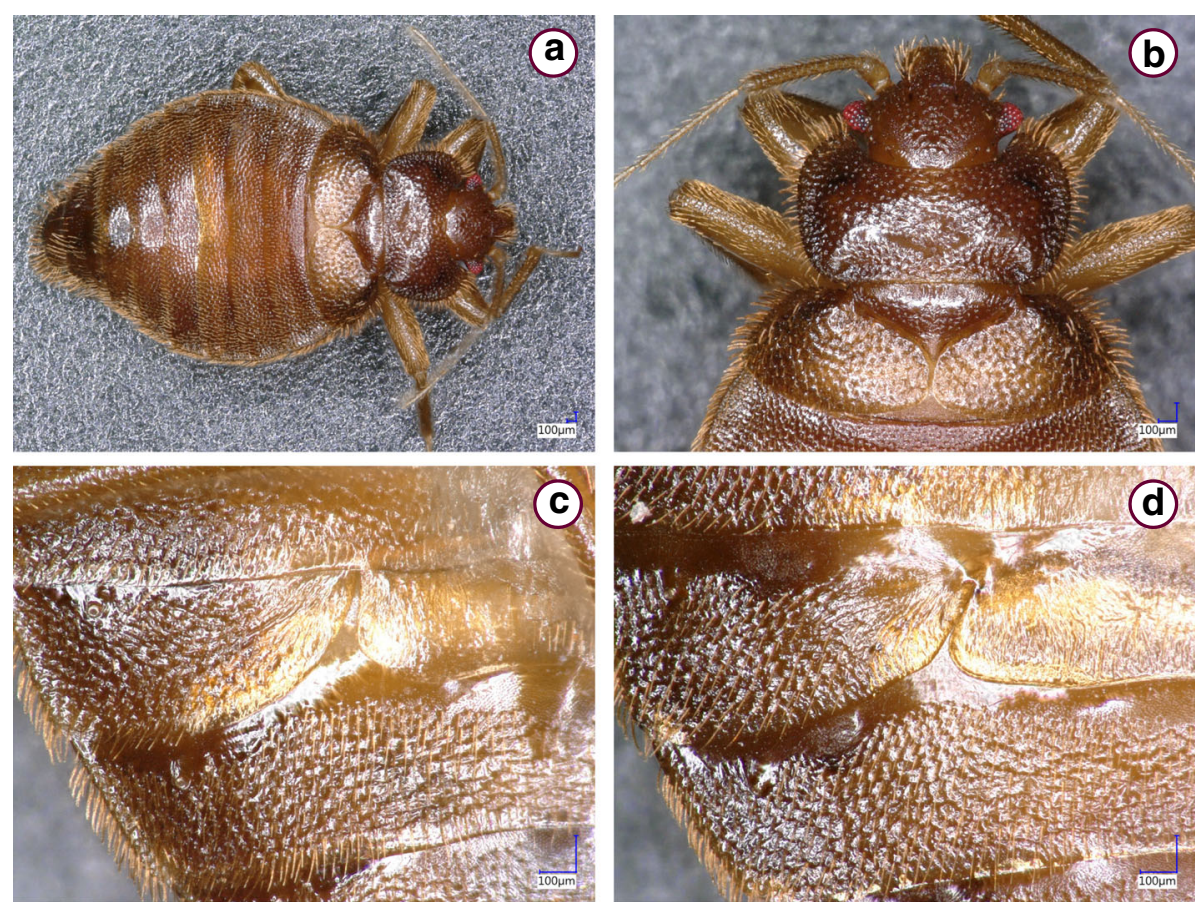

Fig. 5 Cimex pipistrelli, female collected near Myotis spp. a-c Specimen collected in Hungary (Szőlősardó). a Habitus. b Head and pronotum. c Paragenital sinus. d Specimen collected in Romania (Leghia), paragenital sinus 

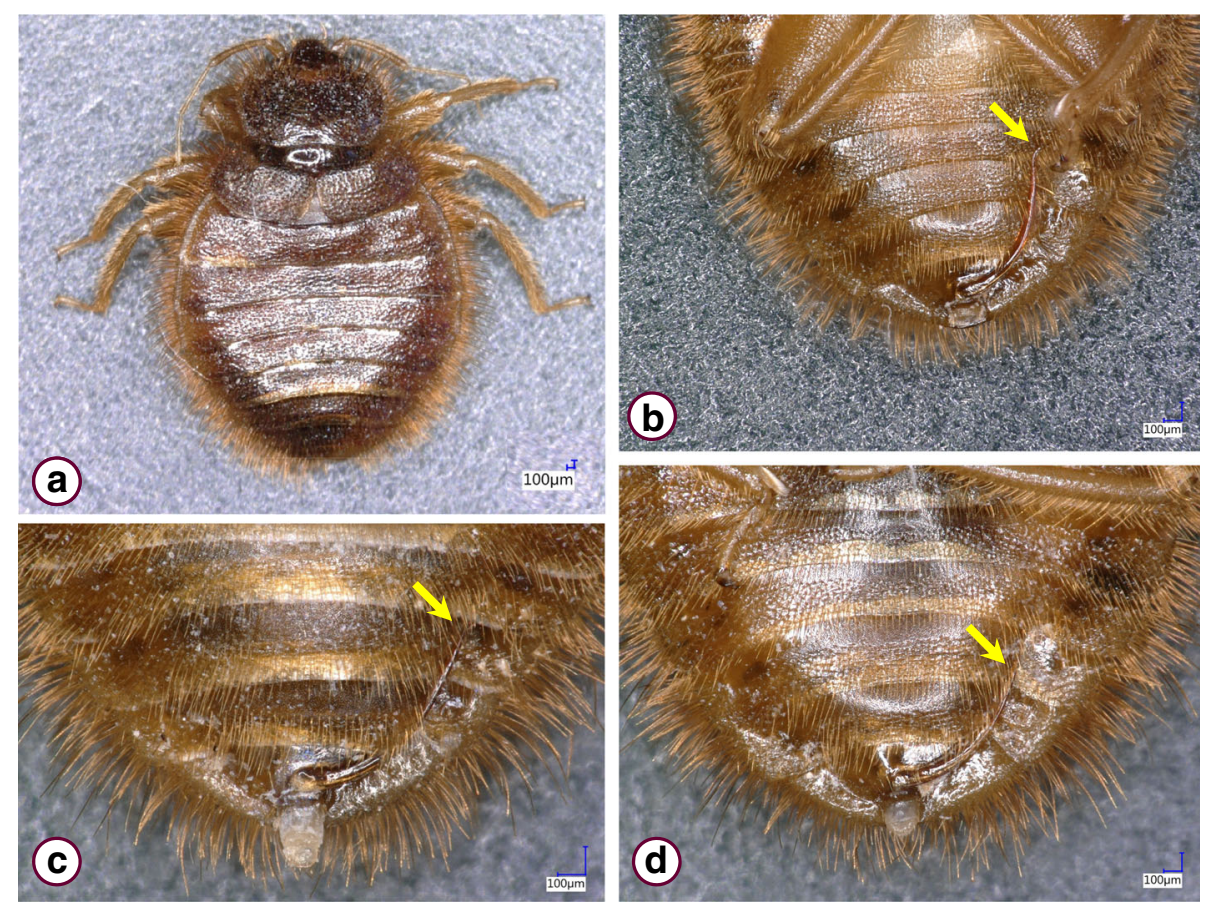

Fig. 6 Cacodmus spp. collected from Pipistrellus hesperidus in South Africa (Makhado). a Ca. ignotus, habitus. b Ca. sparsilis male with long (> $1000 \mu \mathrm{m})$ paramere, curved apically. c Ca. ignotus male with medium length paramere $(850 \mu \mathrm{m})$. d Ca. ignotus male with slightly longer paramere $(950 \mu \mathrm{m})$. Arrows indicate paramere apex

lectularius group was highly supported (with 100\%) in both the cox1 and ITS2 phylogenetic analyses (Figs. 7 and 8). Similarly, the within-group separation of Cimex sp. from Vietnam received high (99\%) support based on its ITS2 haplotype (Fig. 8), but only low (59\%) support based on its cox1 haplotype (Fig. 7).

All Ci. pipistrelli cox 1 haplotypes belonged to the same group with other conspecific isolates (Fig. 7), and this was confirmed in the phylogenetic analysis based on ITS2 sequences (Fig. 8). Bugs identified morphologically as $\mathrm{Ca}$. ignotus and $\mathrm{Ca}$. sparsilis were well separated from each other (with moderate, $87 \%$ bootstrap value) in the cox1 phylogenetic tree (Fig. 7).

\section{Discussion}

This study provides molecular data of bat-associated cimicid bug species from three distant regions of the Old World (i.e. central-eastern Europe, south-eastern Asia and South Africa). One of the studied bug species, Ci. lectularius is the most significant member of Cimicidae, taking into account its association with humans, global distribution, historical and economic impact, recently witnessed emerging character and potential health hazards [6]. In a recent study on Ci. lectularius [9] mostly central and western Europe were represented by sampling sites, therefore results shown here can be regarded as complementary to that study, introducing samples from more locations in Hungary, as well as samples from Romania and Vietnam into the phylogenetic analysis of this species group. In addition, molecular analyses of Cacodmus spp. from South Africa have not yet been reported.

In this study all Ci. pipistrelli, and the majority of $\mathrm{Ci}$. lectularius were collected in roosting places of Myotis spp., which can be regarded as their principal hosts [11]. Only one Ci. lectularius (from M. bechsteinii), the Cimex spp. (from Hungary, Vietnam) and Cacodmus spp. were found on hosts, in particular on four bat species, three of which are pipistrelloid bats (including Hypsugo [formerly Pipistrellus] pulveratus). According to literature data, bat species (such as Pipistrellus and Nyctalus spp.), which roost in narrow spaces (rock crevices or tree holes) and switch these places quite often, are more likely to carry bat-associated bugs on their wing membrane [12]. This is confirmed by the data presented here, taking into account the roosting behavior of the four bat species, which were found bug-infested (Table 1). In addition to $P$. pipistrellus, $P$. hesperidus colonies can also be found in narrow cracks and dead trees [17]. Myotis bechsteinii is a tree-dwelling bat species; its females establish their maternity colonies in tree holes and switch their day-roosts regularly $[18,19]$.

In the present study two new genotypes (belonging to the $\mathrm{Ci}$. lectularius group, but highly divergent from its other members) were identified. Both of the relevant specimens were collected from pipistrelloid bat hosts. The first of these specimens, collected from $P$. pipistrellus in 


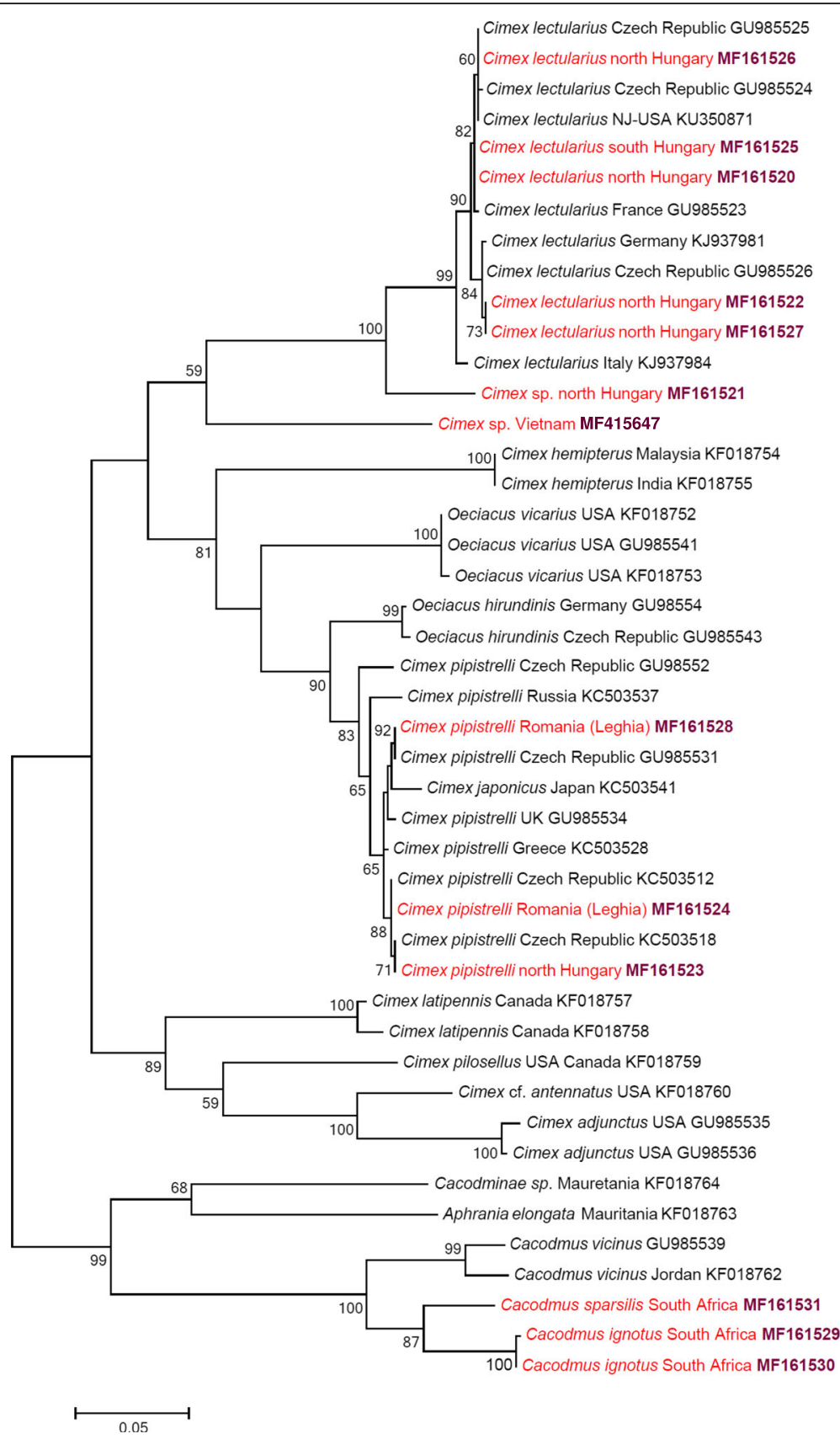

Fig. 7 Phylogenetic tree based on the cox 1 gene including sequences obtained in this study (indicated in red and with GenBank accession numbers in bold) and representative sequences from GenBank. Species identification is provided as in the GenBank database, although Oeciacus spp. were recently transferred into the genus Cimex [4]. Branch lengths represent the number of substitutions per site inferred according to the scale shown

Hungary, showed the morphology of $C i$. lectularius and was different from $\mathrm{Ci}$. emarginatus (e.g. in the parameters of its head, palpal segments, posterior bristles and the shape of paragenital sinus). The second specimen, collected from $H$. pulveratus in Vietnam, was also similar to Ci. lectularius based on its coxal spur and some aspects of its pronotum (which was 2.5 times broader than long, unlike that of Ci. insuetus). However, the paragenital sinus of the latter female was different from that in Ci. lectularius, i.e. it was rounded, which is a character of Neotropical species of the genus Cimex, not found in the Old World [2]. In addition, taking into account that in case of both of these new variants the cox 1 genetic difference exceeded $7 \%$ in comparison with Ci. lectularius (and this value was 5.8-6.4\% between $\mathrm{Ci}$. lectularius and members of the $\mathrm{Ci}$. hemipterus or Ci. pipistrelli species groups, see [4]), they probably represent new species. In order to clarify the precise taxonomical status of these new genotypes, they will 


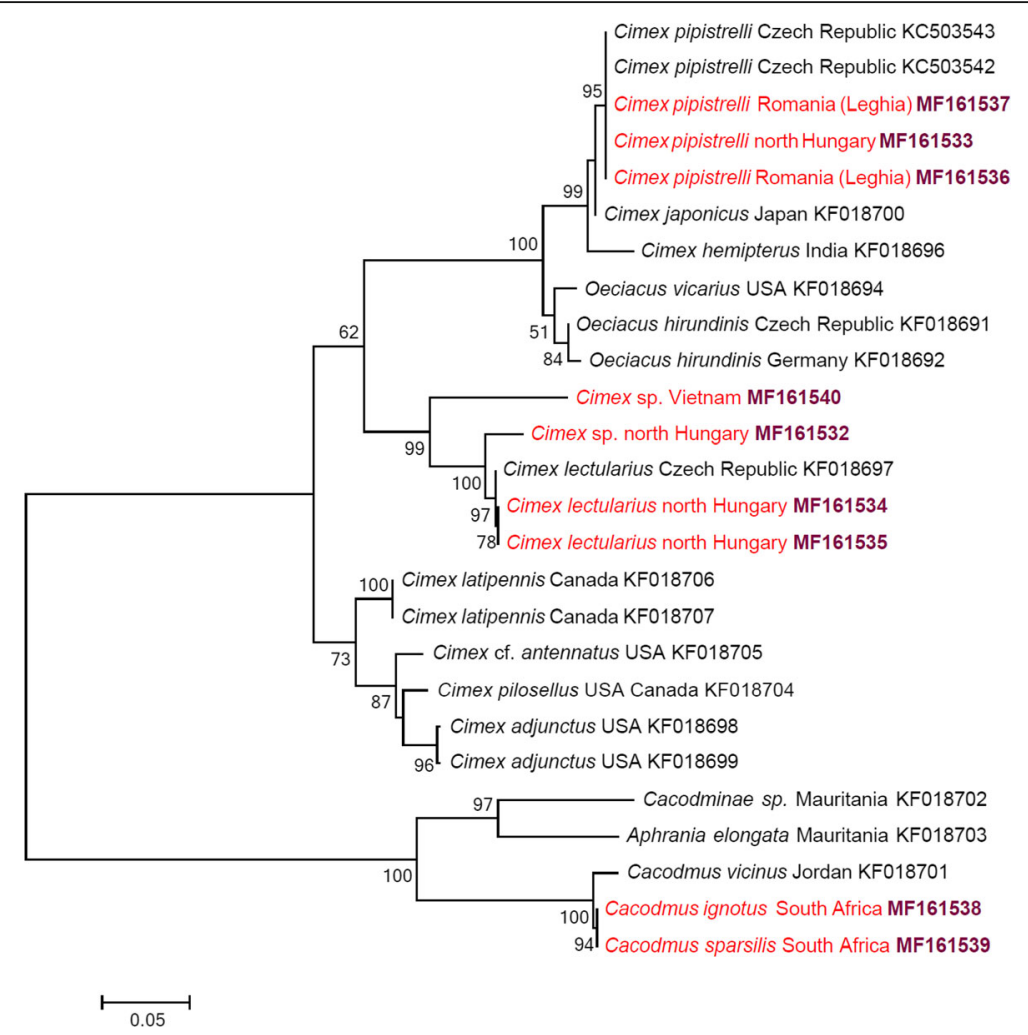

Fig. 8 Phylogenetic tree based on the ITS2 including sequences obtained in this study (indicated in red and with GenBank accession numbers in bold) and representative sequences from GenBank. Species identification is provided as in the GenBank database, although Oeciacus spp. were recently transferred into the genus Cimex [4]. Branch lengths represent the number of substitutions per site inferred according to the scale shown

have to be compared by including more specimens and analyses.

While Ci. lectularius from roosts of Myotis spp. yielded multiple haplotypes within the same major haplogroup [9], in the present study Ci. lectularius-related specimens from pipistrelloid bats showed highly divergent $\operatorname{cox} 1$ and ITS2 haplotypes at both small and large geographical scales (i.e. in Hungary and Vietnam, respectively). This phenomenon is similar to the one suggested in the case of bat-associated bugs of the $\mathrm{Ci}$. pipistrelli group, which were also shown to have different host ranges [2], although the association of Ci. pipistrelli with different host species is thought to be a driver of morphological (rather than genetic) variability [5].

The present results extend the geographical range of $\mathrm{Ca}$. ignotus (hitherto only reported from Uganda, see [2]) to South Africa. This can be explained by the occurrence of $P$. hesperidus (from which it was collected in the present study) in much of East Africa, from Ethiopia to South Africa [20]. However, it was unexpected to find that batassociated bugs identified here on a morphological basis as $\mathrm{Ca}$. ignotus and $\mathrm{Ca}$. sparsilis had highly (6.8\%) different cox1, but identical ITS2 sequences. This observation is similar to that reported previously in the Western Palaearctic region on $\mathrm{Ci}$. pipistrelli, which had only limited variability in ITS2 sequences (and none in other nuclear markers), despite the separation of corresponding cox 1 haplogroups [5]. In general, the resolution of cox 1 analysis to assess the degree of divergence between closely related species is known to be much higher compared to ITS2 (ticks: 6.1 vs $2.3 \%$; mites: $3.0-4.0 \%$ vs $<0.5 \%$, respectively) [21, 22]. Nevertheless, in the present case, the identity of ITS2 sequences between individuals of two Cacodmus spp. could have resulted from genetic introgression or hybridization.

\section{Conclusions}

Bugs of the Ci. lectularius group associated with different bat host species (myotines vs pipistrelloid bats) were found to belong to different genetic lineages. Sequence comparisons and phylogenetic analyses of cox 1 and ITS2 sequences of specimens from pipistrelloid bats (collected in Hungary and Vietnam) suggest that they may belong to new species. In addition, Ca. ignotus is reported for the first time in South Africa.

\section{Abbreviations}

cox1: Cytochrome $c$ oxidase subunit 1; ITS2: Internal transcribed spacer 2

\section{Acknowledgements}

The study was organized in the framework of EurNegVec COST action TD1303. The authors are grateful to Alexandre Hassanin (Institute of Systematic Evolution and Biodiversity, Sorbonne University, Paris, France) for providing the sample 
collected in Vietnam by VIT. Thanks to SARChl Chair in Ecosystem Health (Prof. Wilmien J. Luus-Powell), University of Limpopo for supporting AH and Prof. Peter J. Taylor for helping AH for collecting the samples.

\section{Funding}

Molecular analyses were funded by OTKA 115854 (Hungary). The collection in Vietnam was supported by the Rufford Foundation (UK), and SDA by Domus Hungarica. The publication of this research was supported by the 12,190-4/2017/FEKUTSTRAT grant of the Hungarian Ministry of Human Capacities.

\section{Availability of data and materials}

The sequences obtained and/or analyzed during the current study are deposited in GenBank under accession numbers MF161520-MF161531 (Cox1), and MF161532-MF161540 (ITS2). All other relevant data supporting the conclusions of the article are included within the article.

\section{Authors' contributions}

SH initiated and organized the study and wrote the manuscript. KS extracted the DNA and contributed to bat-related parts of the manuscript. SAB, ADS, $V T T, A H, T G$ and PE collected unique and/or high number of samples for the study. JK made pictures and performed phylogenetic analyses. NT carried out molecular analyses. All authors read and approved the final manuscript

\section{Ethics approval and consent to participate}

Permission for bat capture was provided by the National Inspectorate for Environment, Nature and Water (Hungary), the Vietnamese Ministry of Agriculture and Rural Development (Vietnam Administration of Forestry), and the Underground Heritage Commission (Romania). Bat banding license numbers are 59/2003 (PE), TMF-513/1/2004 (SAB), 305/2015 (ADS) and TMF493/3/2005 (TG)

\section{Consent for publication}

Not applicable.

\section{Competing interests}

The authors declare that they have no competing interests.

\section{Publisher's Note}

Springer Nature remains neutral with regard to jurisdictional claims in published maps and institutional affiliations.

\section{Author details}

'Department of Parasitology and Zoology, University of Veterinary Medicine, Budapest, Hungary. ${ }^{2}$ Department of Nature Conservation, Aggtelek National Park Directorate, Jósvafő, Hungary. ${ }^{3}$ Department of Parasitology and Parasitic Diseases, University of Agricultural Sciences and Veterinary Medicine, Cluj-Napoca, Romania. ${ }^{4}$ Plant Protection Institute, Centre for Agricultural Research, Hungarian Academy of Sciences, Budapest, Hungary. ${ }^{5}$ Institute of Ecology and Biological Resources, Vietnam Academy of Science and Technology, Hanoi, Vietnam. ${ }^{6}$ Department of Biodiversity, School of Molecular and Life Sciences, University of Limpopo, Sovenga, South Africa. ${ }^{7}$ Department of Zoology, Hungarian Natural History Museum, Budapest, Hungary. ${ }^{8}$ Department of Zoology, Eszterházy Károly University, Eger, Hungary.

Received: 12 July 2017 Accepted: 10 September 2017 Published online: 21 September 2017

\section{References}

1. Henry TJ. Biodiversity of Heteroptera. In: Foottit RG, Adler PH, editors. Insect biodiversity: Science and society. Oxford: Blackwell Publishing; 2009. p. 223-63.

2. Usinger RL. Monograph of Cimicidae. Maryland: College Park. Entomol Soc America; 1966. p. 585

3. Balvín $O$, Munclinger $P$, Kratochvíl L, Vilímová J. Mitochondrial DNA and morphology show independent evolutionary histories of bedbug Cimex lectularius (Heteroptera: Cimicidae) on bats and humans. Parasitol Res. 2012;111:457-69.

4. Balvín O, Roth S, Vilímová J. Molecular evidence places the swallow bug genus Oeciacus Stål within the bat and bed bug genus Cimex Linnaeus (Heteroptera: Cimicidae). Syst Entomol. 2015;40:652-65.
5. Balvín O, Vilímová J, Kratochvíl L. Batbugs (Cimex pipistrelli group, Heteroptera: Cimicidae) are morphologically, but not genetically differentiated among bat hosts. J Zool Syst Evol Res. 2013;51:287-95.

6. Zorrilla-Vaca A, Silva-Medina MM, Escandón-Vargas K. Bedbugs, Cimex spp: their current world resurgence and healthcare impact. Asian Pac J Trop Dis. 2015;5:342-52.

7. Wendt A. Über Cimex pipistrelli Jenyns und seine Formen (hex., Rhynchota). Zeitschr Parasitenk. 1941;12:259-72

8. Simov N, Ivanova T, Schunger I. Bat-parasitic Cimex species (Hemiptera: Cimicidae) on the Balkan peninsula, with zoogeographical remarks on Cimex lectularius Linnaeus. Zootaxa. 2006:1190:59-68.

9. Booth W, Balvín O, Vargo EL, Vilimová J, Schal C. Host association drives genetic divergence in the bed bug, Cimex lectularius. Mol Ecol. 2015;24:980-92.

10. Heise G. Zum Transport von Fledermauswanzen (Cimicidae) durch ihre Wirte. Nyctalus. 1988:2:469-73.

11. Balvín O, Bartonička T, Simov N, Paunovic M, Vilímová J. Distribution and host relations of species of the genus Cimex on bats in Europe. Folia Zool. 2014;63:281-9.

12. Balvín $\mathrm{O}$, Ševčik M, Jahelková H, Bartonička T, Orlova M, Vilímová J. Transport of bugs of the genus Cimex (Heteroptera: Cimicidae) by bats in western Palaearctic. Vespertilio. 2012b;16:43-54.

13. Ueshima N. New species and records of Cimicidae with keys (Hemiptera). Pan Pac Entomol. 1968:44:264-79.

14. Folmer $\mathrm{O}$, Black $\mathrm{M}$, Hoeh $\mathrm{W}$, Lutz $\mathrm{R}$, Vrijenhoek R. DNA primers for amplification of mitochondrial cytochrome c oxidase subunit I from diverse metazoan invertebrates. Mel Marine Biol Biot. 1994:3:294-9.

15. Hornok S, Takács N, Szőke K, Kunz B. First record of Ixodes ariadnae in Germany. Acta Vet Hung. 2015:63:347-51.

16. Ji Y-J, Zhang D-X, He L-J. Evolutionary conservation and versatility of a new set of primers for amplifying the ribosomal internal transcribed spacer regions in insects and other invertebrates. Mol Ecol Notes. 2003;3:581-5.

17. Taylor P. Order Chiroptera/bats. In: Skinner J, Chimimba C, editors. The mammals of the southern African sub-region. Cambridge: Cambridge University Press; 2005. p. 256-357.

18. Dietz M, Pir JB. Distribution and habitat selection of Myotis bechsteinii in Luxembourg: implications for forest management and conservation. Folia Zool. 2009:58(3):327-40.

19. Kerth G, Wagner M, König B. Roosting together, foraging apart: information transfer about food is unlikely to explain sociality in female Bechstein's bats (Myotis bechsteinii). Behav Ecol Sociobiol. 2001;50:283-91.

20. Kearney T. Pipistrellus hesperidus. In: Kingdon J, Happold D, Butynski T, Hoffmann M, Happold M, Kalina J, editors. Mammals of Africa. London: Bloomsbury Publishing; 2013. p. 630.

21. LV J, Wu S, Zhang Y, Chen Y, Feng C, Yuan $X$, et al. Assessment of four DNA fragments (COI, 165 rDNA, ITS2, 12S rDNA) for species identification of the Ixodida (Acari: Ixodida). Parasit Vectors. 2014;7:93.

22. Navajas M, Boursot P. Nuclear ribosomal DNA monophyly versus mitochondria DNA polyphyly in two closely related mite species: the influence of life history and molecular drive. Proc Biol Sci. 2003;270(S1):124-7.

\section{Submit your next manuscript to BioMed Central and we will help you at every step:}

- We accept pre-submission inquiries

- Our selector tool helps you to find the most relevant journal

- We provide round the clock customer support

- Convenient online submission

- Thorough peer review

- Inclusion in PubMed and all major indexing services

- Maximum visibility for your research

Submit your manuscript at www.biomedcentral.com/submit
Biomed Central 